\title{
OCORRÊNCIA E CARACTERIZAÇĀO DE ESTAFILOCOCOS COAGULASE NEGATIVOS EM LEITE DE CABRAS NO ESTADO DO RIO DE JANEIRO
}

\author{
MARCELO VIANA DE CASTRO ${ }^{a}$ \\ MARIA CHARLOTTE ELIZABETHE HUBINGER LANGENEGGER ${ }^{b}$ \\ JEROME LANGENEGGER ${ }^{\text {b }}$
}

\begin{abstract}
CASTRO, M.V. de; LANGENEGGER, M.C.E.H.; LANGENEGGER, J. Ocorréncla e caractertzaçáo de Estafilococos coagulase negativos em leite de cabras no Estado do Rio de Janeiro. Semina: Ci. Agr., Londrina, v. 13, n. 1, p. 15-17, mar. 1992.

\section{RESUMO}

Foram estudadas 298 cabras leiteiras, de diferentes raças, em 10 rebanhos leiteiros no Estado do Rio de Janejro. No "California Mastitis Test" (CMT) 179 (60\%) cabras se apresentaram positivas em um ou dois tetos. Para o estudo bacteriológico foram colhidas 585 amostras de leite, 290 CMT positivas e 295 negativas. Do total destas amostras, estafilococos coagulase negativos foram isolados em 216, predominando as espécies S. epidermidis, S. caprae, S. simulans e S. xylosus.
\end{abstract}

PALAVRAS-CHAVE: Mastite; Estafilococos; Cabras.

\section{1 - INTRODUÇẢO}

A caprinocultura de leite tem se desenvolvido muito nos últimos anos, especialmente nos Estados de Sāo Paulo, Minas Gerais, Paraná e Rio de Janeiro. O aumento da produtividade, decorrente da qualidade zootécnica, vem acompanhado naturalmente de um aumento nas infecçōes mamárias.

Uma grande variedade de microrganismos tem sido associada a etiologia das mastites caprinas com predominåncia para os estafilococos coagulase positivos, estreptococos, Escherichia coli e Corynebacterium pyogenes (Sheldrake et al., 1981). Ao lado destes agentes tradicionalmente causadores de mastite sāo encontrados no úbere, principalmente no canal do teto e cisterna, microrganismos que apresentam pouca ou nenhuma patogenicidade, incluindo nesta categoria os estafilococos coagulase negativos (Pettersen, 1981 e Sheldrake et al., 1981). Entretanto săo muitos os pesquisadores que defendem a inclusão dos estafilococos coagulase negativos no grupo dos agentes causadores de mastite caprina (Smith \& Roguinsky, 1977; Dulin et al., 1983; Poutrel \& Lerondelle, 1983 e Hinckley et al., 1985). Estes autores encontraram altas contagens celulares em tetos infectados, intensas irritaçöes no úbere e significativa diminuição na produçẫo de leite.

Estafilococos coagulase negativos em caprinos de leite foram encontrados em diferentes percentagens em várias partes do mundo (Venugopal \& Paily, 1980; Hunter, 1984; Manser, 1986 e Barcellos et al., 1987).

Com relação a mastite subcilnica, diagnosticada presuntivamente em bovinos com muita segurança através da contagem de células somáticas e "California Mastitis Test" (CMT), observa-se divergenncias quanto a validade destas provas em caprinos (Barcellos et al., 1987; Siddique et al., 1988 e Guimarães et al., 1989).

Este trabalho teve por objetivo verificar a ocorrência de estafilococos coagulase negativos em leite de cabras CMT positivas e negativas assim como determinar as espécies predominantes.

\section{2 - MATERIAL E MÉTODOS}

Animais:

Foram examinadas 298 cabras de diferentes raças, idades e estágios de lactação, pertencentes a 10 rebanhos leiteiros de vários munić́pios do Estado do Rio de Janeiro.

Diagnóstico de Mastite subclfnica:

A mastite subclínica foi diagnosticada na propriedade através do "California Mastitis Test" (CMT) segundo Schalm \& Noorlander (1957).

\section{Colheita das amostras:}

Foram colhidas 290 amostras de leite de quartos positivos no GMT e 295 negativas, perfazendo um total de 585 . As amostras foram colhidas em tubos estéreis com tampa de rosca e transportadas ao laboratório acondicionadas em isopor com gelo. A colheita foi precedida de rigorosa anti-sepsia dos tetos com álcool $70^{\circ}$.

\section{Isolamento e identificaçáo:}

As amostras de leite foram semeadas em placas de ágar sangue ovino à $10 \%$ (AS) e incubadas por 24-48 horas à $37^{\circ} \mathrm{C}$.

A famflia Micrococcaceae foi identificada através das caracteristicas morfologicas, tintoriais e pela prova da catalase.

As amostras caracterizadas como estafilococos foram testadas quanto à produção de coagulase (Meyer, 1966). As negativas foram identificadas bioquimicamente através da hemólise em AS, pigmentaçăo da colônia, teste de sensibilidade a furazolidona, reduçăo de nitrato, prova da fosfatase, oxidase, produção de acetilmeticarbinol e de ácido aeróbico à

a. Aluno do Curso de Mestrado em Microbiologia Veterináría U.F.R.R.J.

b. Pesquisador EMBRAPA - Seropedica, R.J. 
partir de xilose, maltose, manose, trealose, sucrose, turanose, frutose e manitol (Kloos \& Schleifer, 1975; Binder, 1986).

\section{3 - RESULTADOS E DISCUSSÄO}

De 298 cabras pesquisadas, $179(60,0 \%)$ apresentaram resultados positivos na prova do "California vastitis Test", em um ou dois tetos.

$\mathrm{Na}$ tabela 1 verifica-se que das 290 amostras positivas, $192(66,2 \%)$ apresentaram exame bacteriologico positivo e das 295 amostras negativas no CMT, $86(29,1 \%)$ também mostraram crescimento bacteriano.

Barcellos et al. (1987) lograram isolamento bacteriologico em 47 das 101 amostras de leite CMT positivas, uma percentagem bem inferior a deste trabalho. Estes autores acreditam que o grande número de amostras CMT positivas sem crescimento bacteriano se deva ao fato de as cabras apresentarem alta concentraçāo celular, ocasionado pela perda do epitélio alveolar devido a processos fisiologicos.

Poutrel \& Lerondelle (1983) observaram dados bastante semelhantes aos desta pesquisa pois isolaram bacterias em $75 \%$ das amostras CMT positivas. No mesmo trabatho os autores comentam a presença de partículas citoplasmáticas no leite de cabra, provenientes do processo de secreção apбcrina desta espécie. Estas partículas sāo isentas de DNA, nāo interferindo no CMT.

O número relativamente alto de amostras CMT negativas, $86(29,2 \%)$, com isolamento bacteriano pode ser explicado por uma eventual contaminação da amostra na colheita, fase inicial do processo infeccioso menor precisão do CMT para a espécie caprina, ou mesmo por uma baixa resposta inflamatória frente aos patógenos menores.

Do total de 278 amostras de leite positivas no exame bacteriológico, de $242(87,0 \%)$ isolou-se estafilococos sendo 26 amostras $(10,7 \%)$ coagulase positivas e $216(89,3 \%)$ coagulase negativas. Este último grupo representou $77,4 \%$ do total de amostras. Dados similares foram encontrados por Hunter (1984) e Manser (1986) na Escócia e Inglaterra respectivamente, que observaram uma ocorrencia de esfalicocos coagulase negativos em cabras ao redor de $80 \%$.

Das 216 culturas de estafilococos coagulase negativos foram identificados pelas provas bioquimicas utilizadas, 191 $(88,4 \%)$, predominando o $\mathbf{S}$. epidermidis $(44,4 \%), \mathbf{S}$. caprae $(14,3 \%), S$. simulans $(8,3 \%)$ e S. xilosus $(6,1 \%)$, como pode ser verificado na tabela 2. Poutrel (1984) utilizando o esquema de identificaçāo proposto por Devriese (1979), conseguil determinar a espécie em $89,9 \%$ das amostras despontando o S. epidermidis, S. caprae, S. simulans e S. sciuri. Binder em 1986, utilizando praticamente as mes- mas provas deste trabalho, com exceçāo da produçāo aerobica de ácido a partir do manitol e frutose e da produçăo de acetilmetilcarbinol, identificou $97 \%$ das culturas. Predominaram o S. xilosus, S. haemolyticus, S. caprae e S. epidermidis.

No que se refere a patogenicidade, alguns autores colocam em dúvida o envolvimento dos estafilococos coagulase negativos na mastite caprina afirmando que a sua presença no úbere nāo causa irritaçāo nem aumento significativo de células somáticas (Pettersen, 1981 \& Sheldrake et al., 1981). Em contraposiçăo pesquisadores como Smith \& Roguinsky (1977), Dulin et al. (1983), Poutrel \& Lerondelle (1983) e Hinckley et al. (1985) afirmam que estas bacterias podem provocar severas infecçőes da glândula mamária com consequente diminuição na produçăo de leite.

O elevado número de amostras de leite CMT positivas com presença de estafilococos coagulase negativos encontradas neste trabalho demonstram o provável envolvimento destes microrganismos nas mastites caprinas.

TABELA 1

RELAÇĀO ENTRE O CALIFORNLA MASTITIS TEST E EXAME BACTERIOLÓGICO

\begin{tabular}{|c|c|c|c|}
\hline \multirow{2}{*}{ CMT } & \multicolumn{2}{|c|}{ BACTERIOLÓGICO } & \multirow{2}{*}{ TOTAL } \\
\hline & POSITIVO & NEGATIVO & \\
\hline Positivo & $192(66,2 \%)$ & $98(33,8 \%)$ & $290(100 \%)$ \\
\hline Negativo & $86(29,2 \%)$ & $209(70,8 \%)$ & $295(100 \%)$ \\
\hline TOTAL & $278(100 \%)$ & $307(100 \%)$ & 585 \\
\hline \multicolumn{4}{|c|}{$\begin{array}{c}\text { TABELA } 2 \\
\text { IDENTIFICAÇĀO BIOQUIMICA DE } 216 \text { CULTURAS DE } \\
\text { ESTAFILOCOCOS COAGULASE NEGATIVOS ISOLADOS } \\
\text { DE CABRAS CMT POSITIVAS E NEGATIVAS }\end{array}$} \\
\hline \multicolumn{2}{|c|}{ ESPÉCIES } & NÚMERO & PORCENTAGEM \\
\hline \multicolumn{2}{|c|}{ S. epidermidis } & 96 & 44,4 \\
\hline \multicolumn{2}{|c|}{ S. caprae } & 31 & 14,4 \\
\hline \multicolumn{2}{|c|}{ S. simulans } & 18 & 8,3 \\
\hline \multicolumn{2}{|c|}{ S. xyfosus } & 13 & 6,0 \\
\hline \multicolumn{2}{|c|}{ S. saccharolyticus } & 10 & 4,6 \\
\hline \multicolumn{2}{|c|}{ S. haemolyticus } & 8 & 3,7 \\
\hline \multicolumn{2}{|c|}{ S. warneri } & 6 & 2,8 \\
\hline \multicolumn{2}{|l|}{ S. cohnii } & 4 & 1,9 \\
\hline \multicolumn{2}{|l|}{ S. fontus } & 2 & 0,3 \\
\hline \multicolumn{2}{|c|}{$\begin{array}{l}\text { S. hyicus subesp. Hyicus } \\
\text { S. hyicus subesp. Chromogenes }\end{array}$} & 2 & 0,9 \\
\hline \multicolumn{2}{|c|}{$\begin{array}{l}\text { S. hyicus subesp. Chromogenes } \\
\text { Staphyiococcus sp* }\end{array}$} & 1 & 0,5 \\
\hline \multirow{2}{*}{\multicolumn{2}{|c|}{$\begin{array}{l}\text { Staphyiococcus sp* } \\
\text { TOTAL. }\end{array}$}} & 25 & 11,6 \\
\hline & & 216 & 100 \\
\hline
\end{tabular}

- Coagulase negativos nåo identificados pelas grovas utilizadas.

CASTRO, M.V. de; LANGENEGGER, M.C.E.H.; LANGENEGGER, J. Ocurrence and characterizacion of negative coaguiase Staphylococci in milking goats, Rio de Janeiro State. Semina: Cl. Agr., Londrina, v. 13, n. 1, p. 15-17, mar. 1992.

\section{ABSTRACTS}

A total of 298 milking goats of different races were studied in 10 hers in the State of Rio de Janeiro. According to Califomia Mastitis Test (CMT) 179 (60\%) goats were positive in one or two teats. For the bacteriological study 585 milk samples were taken, 290 positives and 295 negatives at CMT. From the total amount of samples, negative coagulase were isolated in 216 , staphylococci predominating the species: $S$. epidermidis, $S$. caprae, $S$. simulans and $S$. $x y l o s u s$.

KEY-WORDS: Mastitis; Staphylococci; Goats. 


\section{REFERẼNCIAS BIBLIOGRAFICAS}

1. BARCELLOS, T.F.S.; SILVA, N.; MARQUES JÚNIOR, A.P. Mastite caprina em rebanhos próximos à Belo Horizonte-MG. I. Etiologia e sensiblildade d antbióticos. II. Métodos de diagnóstico. Arq. Bras. Med, Vet Zoot, 39(2): $307-315,1987$.

2. BINDER, C. Subclinical mastitis in goats with special reference to Micrococaceae. Inaugural-Dissertation, Fachbereich Veterinarmedizin, Justus-Liebig - Universität, Glessen, German Federal Republic, 156p., 1986.

3. DEVRIESE, L.A. Identification of clumping factor negative sthaphylococci isolated from cow's udders. Res. Vet Sci., 23: 313-320, 1979.

4. DULIN, A.M.; PAAPE, M.J.; SCHULTZE, W.D.; WEINLAND, B.T. Effects of parity, stage of lactation, and intramammary infection on concentration of somatic cells and citoplasmic particles in goat milk. J, Dairy Sci, 66(11): 2426-2433, 1983.

5. GUIMARÄES, M.P.M.; CLEMENTE, W.T.; SANTOS, E.C.; RODRIGUES, R. Caracterizaçăo de alguns componentes celulares e bioquímicos do leite para diagnóstico de mamite caprina. Arç. Bras. Med. Vot Zoot, 41(2): 129-141, 1989.

6. HINCKLEY, L.S.; POST, J.E.; DUVAL, M.C. The role of nonhemolytic staphylococci in caprine mastitis. Vet. Mod., $80(11): 76-80,1985$.

7. HUNTER, A.C. Microflora and somatic cell content of goat milk. Vet Fec., 114: 318-320, 1984.

8. KLOOS, W.E. \& SCHLEIFER, K.H. Simplified scheme of routine identification of human Staphylococcus species. J. Clin Microbiot 1(1): 82, 1975.

9. MANSER, P.A. Prevalence causes and laboratory diagnosis of subclinical mastitis in the goat. Vet, Rec., $118(20)$ : 552-554, 1986.

10. MEYER, W. Uber die brauchbarkert des koagulasetestes mit vershiedenen plasmaarten zur differenzierung von Staphylocaccus aureus stammen. Zbl. Bakt f. Abt. Orig., 209: 465-481, 1966.

11. PETTERSEN, K.E. Cell content in goat's milk. Acta Vot. Scand, 22(2): 226-237, 1981.

12. POUTREL, B.; LERONDELLE, C. Cell content of goat milk: CMT, coulter counter and fossomatic for predicting half infection. J. Dain Sci., 66(12): 2575-2579, 1983.

13. POUTREL, B. Udder infection of goats by coagulase-negative staphilococcl. Vet Microbiol., 9: 131-137, 1984.

14. SCHALM, O.W.; NOORLANDER, D.O. Experiments and observation leading to development of the California Mastitis Test. J. Am, Vet, Assoc., 130: 199-204, 1957.

15. SHELDRAKE, R.F.; HOARE, R.J.T.; WOODHOUSE, V.E. Relationship of somatic cell count and cell volume analysis of goat's milk to mammary infection with coagulase-negative staphilococci. J. Dairy Res, $48(3)$ : $393-403,1981$.

16. SIDOMQUE, I.H.; HAFEEZ, M.; GBADAMOSI, S.G. Screening for subclinical mastitis in goats: testing the tests. Vet Med., $83(1): 87-88,1988$.

17. SMITH, M.C. \& ROGUINSKY, M. Mastitis and other diseases of the goat's udder. J. Am Vet Med. Assoc, 171(12): $1241-1248,1977$.

18. VENUGOPAL, K. \& PAILY, E.P. Incidence and aetiology of mastitis in goats. Kerala J. Vet Sci., 11(1): 111-114, 1980.

Recebido para publicaçăo em 04/04/1991 